\title{
Spinal injury in Scotland
}

\author{
P Edmond CBE TD FRCSE
}

Spinal Unit, Edenhall Hospital, Musselburgh, Scotland.

Although it was the experiences from World War I that resulted in the recognition of a need for the improved management of patients with spinal cord injury (SCI), it was the urgency of planning for the second major conflict that resulted in the development of appropriate centres in the United Kingdom. Scotland responded first within the United Kingdom to provide comprehensive care in a unit that was established under the direction of the late Professor Norman Dott within the Neurosurgical Centre at Bangour General Hospital, West Lothian. This unit served the needs of the population of the East of Scotland for many years but in 1958 fragmentation of the service occurred. Although patients with acute spinal or acute head lesions were treated in a centre in the Royal Infirmary of Edinburgh which included head and spinal injury research, rehabilitation of the SCI patients was transferred to Edenhall Hospital, Musselburgh, near Edinburgh.

At Edenhall the links with the 1914/18 conflict were maintained. Edenhall Hospital was created in the grounds of Pinkieburn House (site of the Battle of Pinkieburn, 1547), as a hostel for limbless sailors and soldiers. It was a logical progression of a hospital to develop as a Ministry of Pensions hospital and to become the amputee centre for the region. From these origins, a spinal cord injury service was provided. Meanwhile in the west of Scotland a rehabilitation facility for spinal cord injured patients was created at Philipshill Hospital in Lanarkshire but acute problems were still dealt with by the receiving hospitals.

For 30 years the care of spinal cord injured patients has remained fragmented with acute care usually occurring in local neurosurgical or orthopaedic centres and patients being stabilised before transfer. It was fully recognised that the SCI centres could not function in isolation from other surgical and investigative services and that, in spite of the distances and time involved in transfer of patients in Scotland, a single unit should be provided.

In 1983 approval in principle was granted by the government for the development of a new centre in Edinburgh but this was not progressed, and finally in 1987 agreement was reached that a new purpose built National Spinal Injury Centre would be built in the grounds of the Southern General Hospital, Glasgow.

This new national centre for Scotland is nearing completion and will provide accommodation for 48 patients together with all necessary facilities for acute management through to rehabilitation. The unit will provide ventilatory support and includes a dedicated operating theatre and rehabilitation facilities including a swimming pool and a fully equipped wheelchair sports field.

Transport of patients has not been neglected. The unit will provide a helicopter landing pad with night landing facilities capable of receiving the largest commercial and military helicopters and situated close to Glasgow International Airport. Dedicated ambulance transport is being provided by the Scottish Ambulance Service. The unit will serve all of Scotland including the Highlands \& Islands and therefore good helicopter and fixed wing facilities are essential.

The important change from the existing arrangements is that the new national unit is now situated within a large teaching hospital and has been built adjacent to the world renowned Institute of Neurological Sciences. Patients will have access to the most modern investigative facilities of neuroradiology and neurophysiology and on site there is a comprehensive range of all the specialties which may contribute to care of the $\mathrm{SCl}$ patient.

The opportunity for research has not been 
forgotten. Physical laboratory facilities are being provided and it is hoped that the existing close relationship with the Bioengineering Department of Strathclyde University will develop even further.

Although a new building has been created, the philosophies of care will not necessarily change. The aim is to provide comprehensive care on one site with a programme of lifetime surveillance for the patients. The model of domiciliary support pioneered by Sir George Bedbrook and his team in Perth, Western Australia, has been followed, with liaison nurses covering the Scottish mainland supported by peripheral clinics. The similarity between Australia and Scotland may not be obvious but in both countries patients may have to travel considerable distances to the appropriate centres.

The National Spinal Injury Centre for Scotland will open formally in the summer of 1992, 53 years after the first organised service was provided in Scotland in West Lothian. The future is exciting but emphasis, as now, will remain on those 2 vital important core subjects, education and prevention. All of those involved in this new development wish to congratulate the editor and staff of Paraplegia on this occasion. 